\title{
GÊENEROS, SEXUALIDADES E PRÁTICAS DE LETRAMENTOS LITERÁRIOS: UM OLHAR DECOLONIAL PARA AS LISTAS DE LEITURAS OBRIGATÓRIAS DOS VESTIBULARES
}

\author{
GENDERS, SEXUALITIES AND LITERARY LITERACY PRACTICES: \\ A DECOLONIAL LOOK OF REQUIRED READING LISTS FOR VESTIBULAR \\ EXAMINATIONS
}

\author{
Douglas Vinícius Souza Silva* \\ Rodrigo Corrêa Martins Machado**
}

\section{RESUMO}

O objetivo deste trabalho é, a partir dos preceitos da decolonialidade (QUIJANO, 2005; WALSH, 2009), analisar as listas de leituras obrigatórias de vestibulares, investigando: os efeitos retroativos dessas listas nas práticas de letramentos literários escolares; a diversidade social, étnica, sexual e de gênero que elas promovem; como movimentam o cânone literário escolar; e como contribuem (ou podem contribuir) para uma maior democratização da/na educação literária. Para isso, selecionamos listas dos últimos vestibulares de sete universidades públicas, buscando contemplar instituições de cada região do Brasil. Tomamos as listas de leituras como importante ferramenta de legitimação de autores e obras literárias para o contexto escolar. A análise proposta é qualitativo-interpretativista (MOITA-LOPES, 1994; 2006) e compreende que todas as práticas de letramentos literários são ideológicas (STREET, 2014), o que pressupõe tanto uma investigação em diálogo com os contextos sociais e com os diversos atores/agentes em torno das práticas de letramentos analisadas, quanto uma interpretação que não isole os dados da pesquisa das relações de poder e disputas discursivas exercidas em torno deles. A partir da constatação de que a inclusão promovida por essas listas de obras literárias se limita apenas a determinadas diversidades, procuramos analisar, especialmente, a ausência de autores e obras LGBTQIA+, a fim de compreender as razões dessa ausência e demonstrar o potencial educativo que obras e autores desses grupos sociais poderiam ter na construção de práticas de letramentos literários escolares de reexistência (SOUZA, 2011; WALSH, 2009) para uma educação transgressora (HOOKS, 2017) e democrática.

Palavras-chave: letramentos literários; vestibular; decolonialidades; gênero; sexualidade.

\section{ABSTRACT}

This paper, based on the precepts of decoloniality (QUIJANO, 2005; WALSH, 2009), aims to analyze the required readings lists for college entrance examinations (vestibular) by investigating: the retroactive effects of these lists on school literary literacy practices; the social, ethnic, gender, and sexual diversity they promote; how they move the school literary canon; and how they contribute (or can contribute) to a greater democratization of/in literary education. To this end, we select lists from the latest vestibular examinations of seven public universities, seeking to include institutions from all regions of Brazil. We consider reading lists to be an important tool for legitimizing authors and literary works in the school context. The proposed analysis is qualitative-interpretative (MOITA-LOPES, 1994; 2006) and understands that all literary literacy practices are ideological (STREET, 2014), which presupposes not only an investigation in dialogue with social contexts and with the various actors/agents around the literacy practices analyzed, but also an interpretation that does not isolate the research data from the power relations and discursive disputes exercised around them. From the observation that the inclusion promoted by these lists of literary works is limited only to certain diversities, we seek to analyze, especially, the absence of LGBTQIA+ authors and works, in order to understand the reasons for this absence and to demonstrate the educational potential that works and authors from these social groups could have in the construction of school literary literacies practices of re-existence (SOUZA, 2011; WALSH, 2009) for a transgressive (HOOKS, 2017) and democratic education.

Keywords: literary literacies; vestibular; decolonialities; gender; sexuality.

\section{LETRAMENTOS LITERÁRIOS, POLÍTICAS LINGUÍSTICAS E EDUCACIONAIS COMO OBJETOS DE ESTUDO DA LINGUÍSTICA APLICADA: UMA INTRODUÇÃO}

O debate, aqui proposto, parte das formas como as literaturas estão inseridas nos exames vestibulares de universidades públicas e de como isso afeta retroativamente as práticas de letramentos literários do ensino básico. Sabe-se que, pela importância social e individual que os cursos de ensino superior público, gratuito e de qualidade

\footnotetext{
* Universidade Estadual de Campinas (UNICAMP), Campinas, SP, Brasil. dodo.vinicius.ds@gmail.com Orcid: https://orcid.org/0000-0002-4834-6356

** Universidade Federal de Ouro Preto (UFOP), Ouro Preto, MG, Brasil. rodrigo.machado@ufop.edu.br Orcid: https://orcid.org/0000-0001-7269-1996
} 
detêm, um dos objetivos do ensino médio é aprovar os estudantes nos exames vestibulares e, consequentemente, as escolas buscam acompanhar os conteúdos exigidos pelos exames. No campo da literatura, especialmente, esse efeito retroativo ${ }^{1}$ na educação básica é mais acentuado pela existência de listas de obras literárias de leitura obrigatória, que legitimam determinadas literaturas no ambiente acadêmico e institucional das universidades e das escolas e, ainda, movimentam o mercado editorial ao criarem demanda para a compra das obras listadas.

Partindo desse contexto, nosso objetivo geral é compreender os efeitos das listas de leituras literárias obrigatórias de vestibulares em relação à representatividade de pessoas LGBTIA+. Inicialmente, objetivou-se investigar: a diversidade social, étnica, de gênero, de sexualidade que essas listas promovem; como elas movimentam o cânone literário escolar; e como elas contribuem (ou podem contribuir) para uma maior democratização da/na educação literária. Porém, os resultados iniciais da nossa pesquisa nos levaram a reflexões sobre a ausência de LGBTIA + tanto como autores quanto como personagens ou temas das obras literárias constituintes dessas listas, por isso, um último objetivo se impôs e se destacou, em detrimento dos outros: compreender as razões dessa ausência, demonstrando o potencial educativo que obras e autores LGBTIA+ poderiam ter na construção de práticas de letramentos literários escolares mais democráticas. ${ }^{2}$

É importante destacar a relevância desses objetivos ao considerarmos que, conforme o Grupo Gay da Bahia (GGB), o Brasil é o país onde se registra a maior quantidade de crimes letais contra LGBTIA+ no mundo, seguido por México e EUA. Em 2018, a ONG registrou 420 mortes violentas desse grupo social no país, o que indica uma morte a cada 20 horas (MOTT; MICHELS, 2019). Esse número ainda é agravado quando consideramos a subnotificação, denunciada pelo GGB e atestada pela necessidade da existência dessa ONG para fazer a contagem dos dados, já que o poder público não ocupa essa função e, quando denunciamos uma violência homo-transfóbica, ela é registrada como briga, roubo, agressão verbal ou física, apagando a questão de gênero ou de sexualidade envolvida. O que tais dados indicam é que, para uma pessoa LGBTIA+, viver no Brasil é algo perigoso e violento. Dessa forma, estudar, pesquisar e fomentar discussões acerca de letramentos literários e ensino de literaturas produzidas ou que tematizem respeitosamente a vivência de sujeitos que não se conformam à norma cis-heterossexual é algo urgente e de extrema importância.

O debate que desejamos fomentar se insere no campo indisciplinar da Linguística Aplicada (LA). As pesquisas em ensino de literaturas, educação literária e letramentos literários têm sido discutidas e ampliadas no âmbito da LA e, cada vez mais, ganham força nesse campo. Amorim $(2017$, p. 8) destaca que a discussão sobre o literário como parte da política linguística tem crescido exponencialmente nas esferas nacional e internacional. Assim, os estudos em literaturas na LA surgem como um "campo de atividades que tem por objetivo intervir politicamente sobre a realidade linguística construída em contextos diversos" (AMORIM, 2017, p. 8). Nesse sentido, o presente artigo parte de uma realidade posta, a existência das listas de leituras obrigatórias de vestibulares, compreendendo o conteúdo dessas listas como resultado de políticas linguísticas e educacionais complexas, e busca intervir nessa realidade ao refletir sobre os efeitos sociais e pedagógicos, nas práticas de letramentos literários, da forma como essas listas são construídas.

1. Embora o conceito de efeito retroativo seja amplamente debatido nos estudos de avaliações (SCARAMUCCI, 2004; VICENTINI; 2015) e tenha compreensões complexas, no caso deste artigo, por se tratar concretamente de uma lista de obras que devem ser lidas pelos candidatos aos vestibulares, e não do debate sobre o efeito retroativo do vestibular como um todo, tomamos o conceito em um sentido mais simples, o de estimular que essas obras sejam abordadas/lidas/debatidas ao longo da formação básica escolar dos estudantes que pretendem ser aprovados nos vestibulares.

2. Neste artigo, não nos propomos a pensar uma "literatura LGBTIA+" no sentido de definir critérios para que uma obra seja ou não parte dessa literatura. O que nos propomos é refletir sobre como, concretamente, pessoas LGBTIA+, especialmente estudantes do ensino médio, estariam ou não - se sentiriam ou não - representadas pelas listas literárias dos vestibulares, especificamente no que diz respeito a suas condições de gênero e de sexualidade. O que nos interessa, aqui, não é a representatividade de uma possível "literatura LGBTIA+", como uma (sub)categoria literária, nas listas dos vestibulares, mas como sujeitos subalternizados são ou não são contemplados pela literatura canônica dessas listas. De todo modo, nos contempla a definição de Silva (2019, p. 357 apud, MAZZARO, 2021, p. 1074) da "literatura gay": uma escrita "independente da 'identidade de gênero' de quem produz, que problematiza os desejos, as experiências, os modos como as pessoas se subjetivam fora e dentro do 'molde' heterossexual compulsório que ainda rege as relações de gênero", ou seja, "por sua idiossincrasia semântica do ponto de vista cultural, tem a intenção de revelar uma cultura que foi bastante silenciada, invisibilizada e minorizada". Mazzaro (2021, p. 1074) sintetiza essa definição, considerando a palavra "gay", no contexto em que aparece em Silva (2019), como sinônimo de queer (ou de LGBTIA+, neste artigo), como uma escrita que faça "estranhar' desejos, experiências e subjetivações que se constroem a partir da heteronormatividade" e afirma que a compreensão de "idiossincrasia semântica do ponto de vista cultural" se refere "ao estilo, à história e ao valor da obra literária em questão que, embora não definam essa literatura como gay [queer ou LGBTIA+], não podem ser esquecidos" (MAZZARO, 2021, p. 1075). 
Os letramentos literários se constituem em práticas de linguagem e atos políticos que devem se abrir enquanto possibilidade de ressignificação de sujeitos, espaços sociais e relações com o mundo a partir de uma visão que entenda a literatura como algo em constante abertura a novas interpretações e novos sentidos, em relação dialógica com os leitores e com a sociedade. Tendo isso em mente, percebemos a LA como um espaço fecundo para as problematizações concernentes ao ensino de literaturas. Isso pois compreendemos, junto com Moita Lopes (2006, p. 20), a LA como um campo trans/indisciplinar, que procura investigar os problemas com que se defronta ou constrói "ou criar inteligibilidades sobre eles, de modo que alternativas para tais contextos de usos da linguagem possam ser vislumbradas".

Por dialogar com teorias que têm possibilitado um profundo repensar sobre os modos de produção de conhecimentos nas ciências sociais, buscando compreender nossos tempos e "abrir espaço para visões alternativas ou para ouvir outras vozes que possam revigorar nossa vida social ou por vê-la compreendida por outras histórias" (MOITA LOPES, 2006, p. 23), a LA contribui enormemente para se compreender a contemporaneidade. E, por sua vez, esse pensamento indisciplinar da LA nos permite, juntamente com as leituras sobre decolonialidade e gênero, questionar algumas postulações cristalizadas no cerne do ensino de literaturas, que justificam as escolhas das obras que compõem as listas de leituras obrigatórias dos vestibulares. É o caso, por exemplo, de uma ideia de democracia que se preocupa apenas em levar o cânone literário e a cultura clássica aos alunos pertencentes às classes, etnias e sexualidades subalternizadas, sem se preocupar em legitimar as literaturas, artes e demais produções culturais marginalizadas.

Essa forma de ensino não pode ser vista como um ato altruísta do sistema escolar - permitindo aos estudantes, por exemplo, acesso à língua e aos bens culturais das "altas" esferas de poder -, uma vez que, como nos lembra bell hooks (2017, p. 53), "nenhuma educação é politicamente neutra" ou, segundo Street (2014), nenhuma prática de letramento é neutra/autônoma. Seria por demais ingênuo não questionarmos uma educação "democrática" em que a maior parte das obras que compõem as listas de leitura dos vestibulares e que são levadas à sala de aula é escrita por autores brancos, cis-heterossexuais, de classe média ou alta e ocupantes de lugares importantes nas esferas de poder no país. Esse seria, pois, o primeiro grande incômodo nosso em relação a certo modo de ensinar que se mascara de democrático.

Outro incômodo se relaciona ao discurso amplamente difundido de que os alunos não querem ou não gostam de ler, que preferem as redes sociais ao estudo, especialmente da literatura. Porém, percebemos que, de modo não institucionalizado ou escolarizado, os alunos consomem (para além do sentido capitalista) e produzem trabalhos artísticos e literários não legitimados ou, ainda pior, desprezados pelo ambiente escolar. Por isso, questionamos se o afastamento dos conhecimentos escolares não se dá justamente pelo fato de os jovens não se sentirem representados pela literatura escolar(izada). bell hooks (2017, p. 51) nos lembra que "[...] a maioria de nós frequentamos escolas onde o estilo de ensino refletia a noção de uma única norma de pensamento e experiência, a qual fomos encorajados a crer que fosse universal".

Este artigo surge para que pensemos na construção de possibilidades de ensinos que sejam profundamente democráticas e incluam as mais variadas representações de mundo, de culturas e de vivências. Esta proposição considera a necessidade de nos somarmos aos esforços democráticos para a educação, na práxis e na teoria, o que inclui: questionar os modos de ensino tradicionalmente instituídos; propor ações efetivas para contemplar sujeitos historicamente subalternizados; e combater manifestações de preconceito, especialmente nas políticas educacionais públicas.

Tendo em vista essas necessidades, urgentes em tempos como o que vivemos, no qual há um crescimento vertiginoso do autoritarismo e da censura em nossas instituições, inclusive nas universidades e nas escolas, a proposta deste artigo se justifica por sua relevância política, social e educacional. Sobretudo, por se propor a pensar um ensino democrático e as próprias concepções existentes nas políticas linguísticas e educacionais relacionadas à literatura. Para tanto, a decolonialidade, como desenvolveremos a seguir, se faz essencial. De todo modo, ainda cabem duas perguntas introdutórias: como as universidades e seus vestibulares podem auxiliar a se refletir e propor ensinos democráticos de literaturas nas escolas? De que maneira podemos empreender uma discussão a respeito das obras literárias em que sujeitos subalternizados, especialmente LGBTIA+, dado o recorte deste artigo, assumam protagonismo nas produções e leituras literárias? 


\section{ABORDAGEM TEÓRICO-METODOLÓGICA SOB O OLHAR DECOLONIAL EM LINGUÍSTICA APLICADA}

O debate sobre a concretização de uma sociedade democrática no Brasil e nas sociedades latino-americanas vem ganhando cada vez mais espaço, devido, em grande medida, aos movimentos sociais que publicizam a luta dos diversos sujeitos subalternizados contra o processo colonialista. Tais movimentos nos mostram que uma democracia efetiva se sustenta em uma sociedade em que todos os sujeitos que a constituem têm condições equitativas de viver, pensar e se representar. Para construir tais condições, a crítica literária e a escola ocupam um papel importante. No caso do campo literário, destacam-se as pesquisas que repensem as estruturas que o compõem, bem como que analisem de que modo o poder público e suas instituições contribuem ou não com o status quo estabelecido.

Para a investigação que embasa este artigo, foram selecionadas listas dos vestibulares de 2020 e/ou de $2021^{3}$ de sete universidades públicas, estaduais e federais. O critério inicial para a composição do corpus foi selecionar a maior universidade de cada uma das cinco regiões do país. Porém, como ao longo da última década as universidades aderiram ao Sistema de Seleção Unificada (SISU) por meio da prova do Exame Nacional do Ensino Médio (ENEM), que não apresenta uma lista de obras literárias a serem lidas pelos candidatos, poucas universidades públicas ainda estabelecem leituras obrigatória em seus vestibulares. Isso reduziu as possibilidades de escolha e fez com que não fosse selecionada, necessariamente, a maior instituição da sua respectiva região.

Ao final, as universidades escolhidas foram: Universidade Federal de Santa Catarina (UFSC), Universidade Federal do Paraná (UFPR), Universidade Estadual de Campinas (UNICAMP), Universidade de São Paulo (USP), Universidade Federal do Mato Grosso do Sul (UFMS), Universidade Estadual do Maranhão (UEMA) e Universidade Federal de Roraima (UFRR). É possível observar a presença de duas universidades das regiões sul e sudeste, o que ocorreu na tentativa de maior representatividade do cenário brasileiro quanto às listas de leitura obrigatória nos vestibulares, e essas serem as regiões cujas universidades, especialmente estaduais, mais adotam listas de leitura.

É importante destacar que, com esse critério de seleção, optamos por um olhar panorâmico, ou horizontal, para a problemática que decidimos analisar. Assim, nosso olhar se dá a partir de uma fotografia dos vestibulares brasileiros em sua última edição. Outra opção possível seria investigar verticalmente e diacronicamente uma dessas universidades, analisando as listas dos vestibulares ao longo da história da instituição, a forma como as obras literárias são cobradas nas questões das provas do vestibular, como a literatura dialoga ou não com as questões das outras áreas de conhecimento das provas etc. $\mathrm{Ou}$, ainda, em uma pesquisa maior, realizar tal abordagem vertical em todas essas instituições selecionadas. Porém, para um artigo, a fotografia panorâmica que escolhemos investigar se mostrou representativa o suficiente para compreender as questões que nos interessam. Isso até mesmo porque, se essa fotografia seria um passo inicial, já esbarramos no fato de termos que lidar, analiticamente, com ausências e silêncios de dados sobre o recorte LGBTIA+.

A análise aqui proposta é qualitativo-interpretativista (MOITA-LOPES, 1994; 2006) e compreende que todas as práticas de letramentos literários são ideológicas (STREET, 2014), o que pressupõe tanto uma investigação em diálogo com os contextos sociais e com os diversos atores/agentes em torno das práticas de letramentos analisadas, quanto uma interpretação que não isole os dados da pesquisa das relações de poder e das disputas discursivas exercidas em torno deles. Isso implica a necessidade de assumirmos, enquanto pesquisadores atravessados e afetados pelas práticas pesquisadas, a postura ética de empreender investigações e interpretações comprometidas com a democratização da/na educação literária.

Nesse sentido, acreditamos ser necessário fomentar pesquisas em que tanto uma postura colonialista da crítica literária (que tem reflexos diretos no ensino), bem como os próprios modos de ensinar literaturas sejam questionados. Nos valemos, para tanto, dos estudos da decolonialidade enquanto potência/postura ética e política para se refletir e modificar estruturas fixas no que diz respeito ao ensino de literaturas. Tais estudos contribuem com as análises sobre as imposições coloniais nas estruturas de poder da América Latina, especialmente na construção de uma episteme que legitima modos de saber, ser e pensar de modo norte/eurocêntrico.

As discussões empreendidas a respeito do ensino de literaturas, colonialidade e modernidade fomentaram as investigações teórico-críticas deste artigo e impulsionaram a reflexão sobre práticas em que possamos repensar a colonialidade cis-heteronormativa ainda hoje presente na estrutura escolar e no ensino literário. Para nossos propósitos,

3. Devido à pandemia no ano de 2020, algumas universidades cancelaram ou adiaram seus vestibulares. Algumas delas aderiram ao SISU e outras suprimiram as listas de leitura anteriormente divulgadas. Por isso, a lista de alguns vestibulares é da edição de 2020 e não da última edição, de 2021. 
não se trata de propor a renúncia ao cânone literário, estabelecido e reproduzido nas listas dos vestibulares, em nome das literaturas consideradas periféricas, mas de reivindicar a convivência, no mesmo espaço, com a mesma legitimidade e simetria, das múltiplas manifestações culturais representativas da sociedade. Assim, assumimos a compreensão da leitura como ferramenta para a plena democratização cultural, possibilitando a distribuição e a legitimação equitativa dos bens simbólicos.

A fundamentação teórica do artigo dialoga com a proposta metodológica de análise qualitativo-interpretativista, já que, tanto a interpretação que lançamos das listas dos vestibulares, quanto nossa proposição prática de inclusão de pessoas LGBTIA+, se nutrem das reflexões teóricas decoloniais e buscam contribuir com os estudos desse campo teórico. Base teórica e prática metodológica de pesquisa fundem-se não pela simples aplicação da teoria a um objeto da realidade imediata que ateste ou comprove as teorias decoloniais, mas pelos atravessamentos possibilitados pela leveza de pensamento transdisciplinar $(\mathrm{ROJO}, 2006)$ no olhar para os problemas sociais investigados. Com isso queremos dizer que a leitura de estudos decoloniais afeta a nossa percepção sobre os problemas presentes nas listas de leitura obrigatória dos vestibulares, ao passo que os incômodos causados pelos problemas identificados nessas listas nos ajudam a construir reflexões teóricas que contribuam com o campo dos estudos decoloniais. E, ainda no campo dos afetos e atravessamentos, nós, pesquisadores que se identificam como homossexuais cisgêneros, expomos, sem constrangimento e em conformidade com o que defende Rajagopalan (2003, p. 18) no trecho a seguir, que nossas leituras e análises se dão a partir desse lugar LGBTIA+, marcadamente ideológico, na defesa de uma educação literária livre de preconceitos:

as teorias que defendemos refl[e]t[e]m os anseios do momento histórico em que propomos e defendemos as nossas ideias. Em outras palavras, percebe-se a perfeita compatibilidade entre a ciência e um posicionamento político ideológico.

Obviamente, isso implica que tenhamos "clareza sobre as implicações éticas de nossas escolhas teóricas, assim como precisamos ter consciência dos limites do alcance teórico de nosso trabalho" (MOITA LOPES, 2006, p. 98). Daí a necessidade de situarmos o lugar de onde partem nossas interpretações para evidenciar seus limites.

Os pressupostos da decolonialidade muito nos auxiliam a investigar o sistema eurocêntrico com o qual buscamos romper, dando-nos uma ampla perspectiva a respeito das hierarquizações historicamente constituídas. Dois conceitos são primordiais no pensamento decolonialista: colonialidade do poder e modernidade. Para compreendêlos recorremos a Quijano (2005) sobre o debate racial, que pode ter muitas equivalências com o debate de gênero e de sexualidade no que diz respeito à colonização dos corpos. Conforme o pensador, a América constitui-se como a primeira ideia de identidade da modernidade, sendo o primeiro espaço/tempo de um padrão de poder de vocação mundial. Dois eixos históricos convergiram e estabeleceram-se como eixos fundamentais de um novo padrão de poder: "por um lado, a codificação das diferenças entre conquistadores e conquistados na ideia de raça, ou seja, uma supostamente distinta estrutura biológica que situava a uns em situação natural de inferioridade em relação a outros" e "por outro lado, a articulação de todas as formas históricas de controle do trabalho, de seus recursos e de seus produtos, em torno do capital e do mercado mundial" (QUIJANO, 2005, p. 107).

Quijano postula que a ideia de raça, em seu sentido moderno, não tem nenhuma história conhecida antes da América, sendo construída como referência a supostas diferenças de estrutura biológica entre conquistadores e conquistados. Por sua vez, as relações sociais fundadas nessas diferenças produziram identidades sociais novas na América, tais como a de índios, negros e mestiços, também redefinindo outras. Raça e identidade racial foram estabelecidas como instrumento de classificação social da população. Surge, assim, a possibilidade de se valer da teoria decolonial de Quijano para interpretar a (des)classificação social de sujeitos LGBTIA+ e o consequente apagamento dessa população até mesmo no campo da literatura. ${ }^{4}$

Segundo Quijano (2005, p. 107), "os dominantes chamaram a si mesmos de brancos", a ideia de raça, aqui também emprestada para a imposição normativa de gêneros e sexualidades padrões, foi uma maneira de dar legitimidade às relações de dominação impostas pelo colonialismo, tornando-se mesmo uma condição necessária para a existência da colonialidade do poder e dando início ao que modernamente conhecemos como racismo: uma raça

4. Uma aproximação semelhante entre as concepções de raça, de sexualidade e de gênero foi interpretada pelo Supremo Tribunal Federal (STF) ao decidir que homofobia e transfobia se inserem no que é previsto na lei antirracismo, como divulgado pelo portal da instituição: "o conceito de racismo ultrapassa aspectos estritamente biológicos ou fenotípicos e alcança a negação da dignidade e da humanidade de grupos vulneráveis" (STF, 2019, n.p.). 
- ou gênero e sexualidade - julga-se superior às outras em razão de uma suposta superioridade em termos de língua, cultura, sistemas de conhecimento, crenças e práticas sociais.

Os europeus imaginaram-se sendo a culminação de uma trajetória civilizatória, pensando-se como os modernos da humanidade e de sua história, criadores e portadores da modernidade. A elaboração intelectual do processo de modernidade chegou a produzir perspectivas de conhecimento que demonstram o caráter colonial/ moderno, capitalista e eurocentrado de maneira mundial (QUIJANO, 2005). O eurocentrismo teve como objetivo homogeneizar as formas básicas de existência social de todas as populações e seus domínios, o que implicou em estratégias para controle dos poderes, dos saberes, dos modos de ser, de se compreender os gêneros e as sexualidades das populações colonizadas, isto "quer dizer, as mudanças ocorrem em todos os âmbitos da existência social dos povos, e portanto de seus membros individuais, tanto na dimensão material como na dimensão subjetiva dessas relações" (QUIJANO, 2005, p. 114).

Tal homogeneização nos âmbitos sociais e individuais, que impôs padrões de raça, gênero e sexualidade, é demonstrada por Fernandes (2017) ao pesquisar a colonização da sexualidade indígena por parte dos portugueses. Fernandes (2017) defende que houve uma imposição da heterossexualidade aos povos indígenas que, anteriormente, não compreendiam gênero e sexualidade nas categorias atuais e, consequentemente, não operavam suas relações no processo de inferiorização, presente nos ocidentais discursos cristãos - sobre o pecado - e científicos - de patologização de sexualidades e gêneros não padrões.

Dessa forma, o domínio do poder por parte dos países da Europa não só impôs novas formas de se relacionar com o Outro, consigo mesmo e com a cultura, como também o fez na medida em que estimulava o apagamento das subjetividades, sexualidades, gêneros, culturas, línguas, modos de se relacionar e de ver o mundo dos povos colonizados. Até mesmo a visão desses povos em relação à natureza que os cercava passa a ser subjugada e diminuída em prol do que se conhece como "cientificidade".

O pensamento que busca subjugar e apagar aquilo que não consegue compreender fez com que os saberes dos povos colonizados também fossem silenciados, quando não roubados e vendidos como europeus. Existe uma desconsideração dos milenares conhecimentos filosóficos, artístico-literários e na ciência agrícola produzidos na África, na América e na Ásia, entre muitos outros modos de saber. O "conhecimento" foi, por seu caráter e origem eurocêntrico, denominado "racional", imposto ao conjunto do mundo capitalista como única racionalidade válida e emblema da modernidade. Mas a revolta contra a perspectiva e o modo eurocêntrico de produzir conhecimento nunca esteve exatamente ausente, em particular na América Latina, configurando justamente o que vem sendo denominado como decolonialidade (QUIJANO, 2005).

Trazendo o olhar decolonial para o contexto contemporâneo, de persistência da colonialidade, Walsh (2009, p. 8) aponta para os problemas da política "multicultural" que, para ela, é apenas uma estratégia do mundo moderno para incluir os anteriormente deixados de fora em um modelo globalizado de sociedade, sem abalar as estruturas sociais e os interesses mercadológicos. A estudiosa ressalta que as estratégias multiculturais de inclusão não buscam e nem se interessam por transformar as estruturas sociais racializadas, ao contrário, têm como objetivo administrar a diversidade diante do que é visto como "perigo de radicalização de imaginários e agenciamentos". Ou seja, a política multicultural ainda seria uma apropriação das culturas subalternizadas pelo neoliberalismo não com fins de incluir, senão de controlar os sujeitos potencialmente rebeldes.

Para Walsh (2009), mesmo quando está presente no discurso, o dito reconhecimento e respeito à diversidade cultural, sexual e linguística passa a ser uma nova estratégia de dominação que ofusca e mantém a diferença colonial. O discurso "inclusivo" do multiculturalismo se vende como uma ferramenta a serviço de sociedades mais equitativas e igualitárias quando, na verdade, há o desejo de controlar o conflito étnico, sexual e de gênero, e manter a estabilidade social para impulsionar os imperativos econômicos do neoliberalismo.

Grande parte do discurso em torno do ensino de literaturas, perceptível nos critérios de seleção das obras que compõem as listas de leitura obrigatória dos vestibulares, se fundamentam no pensamento colonialista e multicultural debatido por Walsh (2009). Vejamos como isso aparece na seleção das obras que compõem as listas de leitura obrigatórias dos vestibulares: 


\section{LISTAS DE LEITURA OBRIGATÓRIA DE VESTIBULARES: DIVERSIDADE, INCLUSÃO E EFEITOS NA EDUCAÇÃO BÁSICA}

Apresentamos, abaixo, as listas de obras de leitura dos vestibulares selecionados:

- Vestibular da Universidade Federal do Paraná (UFPR) - 2021: O Uruguai, de Basílio da Gama; Últimos Cantos, de Gonçalves Dias; Casa de Pensão, de Aluísio de Azevedo; Clara dos Anjos, de Lima Barreto; Sagarana, de Guimarães Rosa; Morte e Vida Severina, de João Cabral de Melo Neto; Nove Noites, de Bernardo Carvalho; e Relato de Um Certo Oriente, de Miltom Hatoum.

- Vestibular da Universidade Federal de Santa Catarina (UFSC) - 2021: Cemitérios dos Vivos, de Lima Barreto; De amor e Amizade, de Clarice Lispector; Fazendo Modelo, de Chico Buarque; Negro, de Cruz e Sousa; Boca do Inferno, de Ana Miranda; Ânsia Eterna, de Júlia Lopes de Almeida;

- Vestibular da Universidade de Campinas (Unicamp) - 2021: Sonetos escolhidos, de Camões; Sobrevivendo no Inferno, do grupo Racionais Mc's; O Espelho, de Machado de Assis; O Marinheiro, de Fernando Pessoa; A Falência, de Júlia Lopes de Almeida.

- Vestibular da Universidade de São Paulo (USP) - 2021: Poemas Escolhidos, de Gregório de Matos; Quincas Borba, de Machado de Assis; Claro Enigma, de Carlos Drummond de Andrade; Angústia, de Graciliano Ramos; A Relíquia, de Eça de Queiroz; Mayombe, de Pepetela; Campo Geral, de Guimarães Rosa; Romanceiro da Inconfidência, de Cecília Meireles; e Nove Noites, de Bernardo Carvalho.

- Vestibular da Universidade Federal do Mato Grosso do Sul (UFMS) - 2020: Espumas Flutuantes, de Castro Alves; Inocência, de Visconde de Taunay; Quincas Borba, de Machado de Assis; Estrela da Vida Inteira, de Manuel Bandeira; Primeiras Estórias, de Guimarães Rosa; A Hora da Estrela, de Clarice Lispector; Antes do Baile Verde, de Lygia Fagundes Telles; Dois Irmãos, de Milton Hatoum; Cantos da Terra, de Emmanuel Marinho.

- Vestibular da Universidade Federal de Roraima (UFRR) - 2020: O Homem de Barlovento, de Bruno Cláudio Garmatz; Urihi: Nossa Terra, Nossa Floresta, de Devair Fiorotti; Vidas Secas, de Graciliano Ramos; Macunaíma: o herói sem nenhum caráter, de Mário de Andrade.

- Vestibular da Universidade Estadual do Maranhão (UEMA) - 2020: Libertinagem, de Manuel Bandeira; Memórias de Um Sargento de Milícias, de Manuel Antônio de Almeida; Verão no Aquário, de Lygia Fagundes Telles;

As listas de obras e autores acima parecem coerentes com a forma como a literatura tem sido abordada nas escolas. Isso significa dizer que a maior parte dos autores são brasileiros, pertencentes à literatura nacional de períodos variados, com uma expressão menor do século XXI e maior dos séculos XIX e XX. No geral são homens, com expressividade maior de brancos, todos cisgêneros, e praticamente todos publicamente heterossexuais, apesar de um debate, muitas vezes preconceituoso e estereotipado, sobre a sexualidade de Mário de Andrade. Além disso, é possível ler a maior parte dos títulos fazendo o clássico exercício, que não faremos aqui, de dividi-los em escolas literárias, o que atribuiria, até mesmo antes da leitura, características às obras e aos autores. Rezende (2013, p. 101) define essa perspectiva como "tendo da história uma visão muito particular, com resíduos nada desprezíveis do positivismo do século passado e do anterior acrescido de uma visada marxista", que a autora declara estar amparada em Antonio Candido.

De maneira mais específica, ainda que sob o risco de incorrer em essencialismos identitários, é possível descrever o conjunto desses autores da seguinte forma: quanto ao gênero, há 29 autores homens e 5 Mulheres, nenhum/a que se reivindica transexual, travesti ou não binário; quanto à nacionalidade, há 30 brasileiros, 3 portugueses e 1 angolano; quanto à etnia não há nenhum indígenas e poucos autores se reivindicam negros/pretos; quanto à sexualidade, nenhum/a autor/a se reivindica homo, bi ou assexual. Ainda assim, merecerem destaques algumas obras de autores subalternizados e periféricos, como o álbum Sobrevivendo ao Inferno, dos Racionais, por se tratar de uma obra do rap, que tematiza o racismo, a violência policial contra jovens negros, a desigualdade de oportunidades entre brancos e negros e diversos outros assuntos urgentes da contemporaneidade. Destaca-se a obra Mayombe, do Pepetela, já que no cenário global as literaturas africanas, nesse caso, de língua portuguesa, ocupam um espaço marginal. E destaca-se, ainda, algumas obras comumente referidas como "regionais", que representam a literatura de onde as universidades estão situadas, são elas: Cantos da Terra, de Emmanuel Marinho; O homem de Barlovento, de Bruno Cláudio Garmatz; e Urihi: Nossa Terra, Nossa Floresta, de Devair Fiorotti. 
Assim se desenha a ambivalência em torno da existência de listas de leitura obrigatória dos vestibulares. De um lado, como importante instrumento de legitimação e canonização institucional e acadêmica, as listas são responsáveis por movimentar o cânone literário, com base no conhecimento teórico, acadêmico e do pensamento social contemporâneo, incluindo obras marginais, periféricas, contemporâneas e representativas de algumas diversidades sociais brasileiras. Isso configura o potencial transgressor (bell hooks, 2013), possivelmente inserido em práticas de letramentos de reexistência (SOUZA, 2009), que essas listas possuem, já que, além de legitimarem literaturas apagadas de sujeitos precarizados, movimentam o mercado editorial em favor dessas obras e contribuem para que sejam levadas às escolas e façam parte da educação literária das novas gerações. Por outro lado, as listas podem ter um efeito de cristalização das abordagens pedagógicas nas escolas - e isso ocorre principalmente na rede particular de ensino, que se engessa nos moldes dos vestibulares - e, majoritariamente, reforçam o cânone tradicional, com insuficiente inclusão da diversidade de sujeitos subalternos, o que também produz o efeito retroativo, no ensino básico, de apagamento desses sujeitos.

Desenha-se parcialmente a política multicultural, nesse caso linguística e educacional, criticada por Walsh (2009), justamente por ser limitada e construída a partir dos interesses das elites intelectuais e econômicas colonialistas, sem a participação das vozes subalternas. Duas falhas na tentativa de inclusão da diversidade se destacam: a ausência de autores indígenas e a ausência de autores, personagens ou temáticas LGBTIA +. A primeira, a questão indígena, merece um espaço específico para ela e não faz parte do recorte deste artigo, mas não podemos nos desviar desse debate sem ao menos comentá-lo, referenciando Albuquerque (2018), que se dedicou a problematizar o apagamento indígena nos livros didáticos.

A ausência de autores indígenas reduz a diversidade de povos originários a personagens representados de maneira estereotipada. Essa representação, em sua maioria, se dá na chave do índio como herói, como ingênuo, como ser desprovido de razão e de alma, enquanto "poucos são os romances indianistas que tratam do extermínio" (ALBUQUERQUE, 2018, p. 216). Até a década de 70, "a possibilidade de índios escreverem, sobre si literariamente ou não, era mínima", pois "houve sempre quem escrevesse senão sobre os índios, mas em lugar deles" (ALBUQUERQUE, 2018, p. 218). Porém, esse cenário se modifica, lentamente, a partir da década de 80 com a tradução de obras escritas em línguas indígenas para o português,

disso são exemplos Antes o Mundo não Existia (1980), de Umúsin Panlõn Kumu e Tolamân Kenhíri, Mitologia Tariano (1994), de Ismael e Ângelo Moreira e a Coleção Narradores Indígenas, publicada pela Federação das Organizações Indígenas do Rio Negro (FOIRN) em associação com o Instituto Socioambiental (ISA), no período compreendido entre 1990 e 2004 (ALBUQUERQUE, 2018, p. 218)

Além dessas, há inúmeros outros exemplos de obras indígenas citadas pelo autor. Em síntese, para Albuquerque (2018, p. 218-219), a partir desse período, chegamos "no campo da autoria na qual os índios deixam de ser objeto de interesse científico para se constituírem sujeitos com autoridade expressiva sobre o que escrevem", mas isso acabou não sendo legitimado pelo campo das letras e da literatura. A questão que resta é: por que, ainda que a lei $11.645 \mathrm{e}$ a Base Nacional Comum Curricular prevejam o estudo das histórias e das culturas indígenas pela educação básica, obras de autores indígenas não estão incluídas nas listas dos vestibulares, fazendo com que permaneçam apenas no papel de representados, sem a possibilidade de representar?

Como adiantamos, essa pergunta poderia se desdobrar em um artigo específico para ela, mas aqui nos interessa um outro grupo social que, além de, assim como os indígenas, não ter representantes enquanto autores de literatura nas obras escolares, sequer aparece representado, como personagem ou tema, no sentido mais amplos possível, nas obras exigidas pelos vestibulares: as pessoas LGBTIA.$+^{5}$

\section{A CONTRIBUIÇÃO LGBTIA+ PARA UMA EDUCAÇÃO LITERÁRIA DEMOCRÁTICA}

Inicialmente, importa destacar que a análise que tecemos adiante é a partir do silêncio e da ausência de LGBTIA+ nas listas dos vestibulares. Em um primeiro momento, esperávamos analisar as listas em si, mas os gritos

5. Como abordamos na nota $\mathrm{n}^{\mathrm{o}}$ 2, na primeira seção, investigamos as listas de leitura obrigatória procurando, da forma mais ampla possível, autores, personagens ou qualquer forma literária de representar ou de se reconhecer temáticas LGBTIA+. Apesar de a definição de literatura de Silva (2019, apud MAZZARO, 2021) muito nos contemplar, não buscamos nos restringir a uma definição específica de "literatura LGBTIA+" a ser representada. 
por trás do silêncio da diversidade sexual e de gênero nos fez partir para além das listas e analisar os motivos dessa ausência. Dados apresentados na introdução do presente trabalho são preocupantes e alarmantes no que diz respeito ao alto índice de vulnerabilidade da população LGBTIA +. E eles corroboram a nossa afirmação de que os sujeitos que escapam ao padrão hetero-cis-normativo são subalternizados na sociedade brasileira e precisam lutar para sobreviver: a expectativa de vida de uma pessoa trans no Brasil, por exemplo, é de apenas 35 anos (THOMAZ, 2018).

Ao confrontar esses dados com a teoria decolonial, o conceito de colonialidade do ser, desenvolvido por Maldonado-Torres (2007) se destaca. Conforme o autor, a concepção subjacente à colonialidade do ser relacionase à epistemologia e às tarefas gerais implicadas na produção de conhecimento para a reprodução dos regimes de pensamento coloniais, referindo-se às experiências vividas da colonização e seus impactos na linguagem.

As expressões primárias da colonialidade do ser, para Maldonado-Torres (2007), são a invisibilização e a desumanização. Esses aspectos acabam por produzir uma exceção na ordem do ser, no sentido de que se produz o humano e seu mundo em oposição ao não-ser humano e a um mundo inumano. A alteridade humana é violada, sujeitos são apagados, tidos como abjetos, aproximados à ideia de natureza a ser conquistada e dominada. Foi exatamente o que ocorreu com as populações indígenas e negras da diáspora americana: sofreram inúmeros processos de exclusão, silenciamento, escravização e apagamento (e ainda sofrem de muitas maneiras, lutando para serem respeitadas e reconhecidas). Como ressalta o estudioso, a colonialidade do ser se relaciona à produção da linha de cor (a ideia de raça) em suas diferentes expressões e dimensões, produzindo a diferença ontológica colonial.

No caso das mulheres amefricanas e ameríndias, por exemplo, o apagamento é maior, como nos diz Gonzales (2020). A estudiosa brasileira argumenta que essas mulheres carregam o duplo caráter de sua condição biológica (racial e de gênero), fazendo com que elas sejam mais oprimidas e exploradas em um estado capitalista patriarcalracista dependente. Esse sistema acaba por transformar "as diferenças em desigualdades" e "a discriminação que elas sofrem assumem um caráter triplo: dada a sua posição de classe, ameríndias e amefricanas fazem parte, em sua maioria, do proletariado afro-latino-americano" (GONZALES, 2020, p. 46). Não podemos deixar de ressaltar também que, em um país como o Brasil, em que LGBTIA + são sistematicamente violentados, as pessoas nomeadas por essa sigla são consideradas abjetas e, quanto mais se distanciam do que hegemonicamente é posto como homem-mulher-cishetero-padrão-branco e das classes sociais com maior poder aquisitivo, mais violência a elas é dirigida, isto é, também sofrem esse triplo caráter de discriminação: o étnico, o sexual e/ou de gênero e o de classe.

É sintomático que tenhamos como Presidente alguém que venceu a eleição presidencial com uma pauta contrária a discussões de gênero, acompanhando um movimento conservador no Brasil que tentou impor nas escolas um projeto chamado "Escola sem partido", o qual, por sua vez, buscava coibir e constranger qualquer docente ou sistema escolar que discutisse questões referentes à raça, gênero e sexualidade. Tal projeto deu espaço para que professores fossem denunciados sob o pretexto de que a educação básica estava transformando as crianças e adolescentes em LGBTIA+. A ideia defendida pelos idealizadores desse projeto (e seus seguidores) é que haveria uma "ideologia de gênero na escola" e deveriam ser adotadas políticas "neutras". Miskolci (2016, p. 14) nos auxilia a refletir sobre isso quando revela que esse suposto olhar neutro, no qual se baseou a educação até hoje, é heterossexual e imposto, "ninguém ainda pensa na heterossexualidade como algo opcional" e nunca houve uma educação pensada como inclusiva e respeitosa com a diversidade sexual e de gênero.

Junqueira et al (2020, p. 191), ao comentar políticas públicas educacionais, afirma que "a 'agenda' de gênero e sexualidade na educação do governo Bolsonaro é norteada e desenvolvida com base em pressupostos e repertórios de ação de uma ofensiva reacionária antigênero que já estava em marcha". Daí o debate sobre as listas dos vestibulares de universidades públicas e a ausência de questões de gênero e sexualidade, já que as universidades, sendo autarquias, desempenham um papel retroativo na educação básica independente do governo vigente. Afinal, Junqueira et al (2020, p. 211) ainda ressaltam que "lutar contra a ofensiva antigênero nas escolas exige ações micropolíticas que permitam interromper esse roteiro funesto de produção da barbárie educacional". Inserir temáticas LGBTIA+ nas listas dos vestibulares, uma decisão política não tão micro se pensarmos na importância atribuída ao vestibular pela sociedade, legitimaria professores, que não incluíam essas obras em suas salas de aula por medo da perseguição reacionária antigênero, a finalmente levá-las para seus alunos.

Mais recentemente, a Assembleia Legislativa do estado de São Paulo (ALESP) recebeu um projeto de lei 504/2020 cujo objetivo principal é o de proibir a diversidade sexual em peças publicitárias no estado (ALESP, 2020). Esse projeto, também conhecido como "projeto anti-LGBT", tem como principal objetivo invisibilizar os sujeitos LGBTIA + ainda mais e, caso aprovado, oficializará o desejo de que nós não somente voltemos aos armários e aos 
becos, mas que desapareçamos. No texto da proposta, em trâmite desde agosto de 2020, a autora diz que tem o desejo de acabar com propagandas que geram "desconforto emocional a inúmeras famílias, além de estabelecer prática não adequada a crianças" e "a intenção é limitar a veiculação da publicidade que incentive o consumidor do nosso Estado a práticas danosas".

Se nas esferas institucionais, como na ALESP, encontramos esse tipo de discurso violento e antidemocrático sendo feito abertamente, como isso se dá em nossas escolas? De que modo as escolhas não-arbitrárias de obras literárias a serem trabalhadas nas escolas e cobradas em processos de vestibulares podem combater a censura a obras escritas por sujeitos LGBTIA+ ou que tematizem relações hetero-dissonantes? Como apresenta Rocha (2020, p. 124), "a escola não pode se eximir da responsabilidade de educar jovens para o diverso, insidiosamente negligenciando esse processo com a justificativa de que está tomando uma postura 'neutra' e imparcial".

A partir das universidades selecionadas e das listas de obras literárias que elas cobraram em seus processos seletivos, é possível constatar que não há sequer um autor que se reivindique LGBTIA+, tampouco há obras que tematizem esses sujeitos em suas páginas. Esse silêncio significa. Essa ausência é significativa em relação às concepções primárias da colonialidade do ser, de Maldonado-Torres (2007): invisibilização e a desumanização.

No que se refere à invisibilização, talvez seja mais óbvio quando apresentamos esses dados da inexistência de obras, autores, personagens ou temáticas. De alguma maneira, isso é sintomático quanto ao desejo de que não tenhamos voz, nem vez, muito menos espaço para podermos mostrar a todos que existimos, que produzimos literatura, música, arte, que somos seres humanos. Por mais que essa invisibilização carregue consigo a pretensão de que nos escondamos, "o mundo, hoje, o sentimos nosso, também nosso, e já não nos contenta somente armário ou beco nem a sujeição aos padrões cis que nos têm sido impostos" (MOIRA, 2017, n.p.). Há duas instituições principais que devemos destacar nesse processo: a Escola e a Literatura. Ambas com moldes excludentes e pouco democráticos pensadas por e para sujeitos que vivem em modelos euro e norte-cêntricos de relacionamentos. Moira (2017, n.p.) destaca que: "o mundo não foi pensado para nós, suas burocracias, regras, seu apego às máscaras, gavetas trancafiadas, armários; talvez por isso o medo ante essas figuras, nós, que ousamos nos descobrir para além das máscaras que nos pregaram nos rostos".

Pela dissonância aos padrões impostos, as experiências LGBTIA+ são ignoradas: autores não frequentam o cânone e as listas de vestibular, obras são ignoradas, a qualidade do trabalho, da escrita e da força simbólica e política que as literaturas, que tematizem esses sujeitos, possuem não têm a ressonância que deveria. Ignora-se, ainda, as contribuições que essas obras e esses sujeitos trariam para a educação literária.

Nesse sentido, "como já indicou Sedgwick (1990), o silêncio é um ato de fala altamente performativo, pois ele legitima o status quo" (ROCHA, 2020, p. 124). Disfarçado pela neutralidade, esse silêncio produz sexualidades, seja na "celebração e consequente legitimação da heterossexualidade reprodutiva ou pela marginalização de outras práticas sexuais por meio de seu apagamento (ROCHA, 2020, p. 125). Rocha (2020, p. 126) ainda afirma que a escola - e as listas dos vestibulares, neste caso - tem a prática comum de legitimar apenas a cis-heteronormatividade, justamente pelo silêncio, porque "não se fala sobre outras maneiras de exercer a sexualidade" e o gênero.

Se somos invisibilizados, não existimos e, se não existimos, somos desumanizados, despojados de nossas possibilidades de ser, de criar conhecimentos, de compartilhar nossas diversidades de desejos e de corpos. Butler (2017, p. 47) destaca que há uma regulação binária da sexualidade a qual "suprime a multiplicidade subversiva de uma sexualidade que rompe as hegemonias heterossexual, reprodutiva". E, com a emergência dos sujeitos cujo gêneros e sexualidades não se conformam às normas de gênero pelas quais pessoas são definidas, a própria noção de pessoa passa a ser questionada. A maneira que as "pessoas" lidam com isso é desumanizando aqueles que fogem a esse padrão imposto. Como nos diz Lugones (2020, p. 57) "toda forma de controle do sexo, da subjetividade, da autoridade e do trabalho existe em conexão com a colonialidade".

Butler (2017, p. 193 - 194) ressalta ainda que as imagens corporais que não se encaixam nos gêneros hegemônicos, e aqui acrescentamos à sexualidade padrão hétero, ficam fora do humano "constituem a rigor o domínio do desumanizado e do abjeto, em contraposição ao qual o próprio ser humano estabelece". Esses sujeitos são relacionados ao perigo e à poluição: "o 'abjeto' designa aquilo que foi expelido do corpo, descartado como excremento, tornado literalmente 'Outro'. Parece uma expulsão de elementos estranhos, mas é precisamente através dessa expulsão que o estranho se estabelece" (BUTLER, 2017, p. 230).

Os cis-temas escolar e literário, por omissão, ao mesmo tempo impõem aos LGBTIA+ esse lugar de "Outro" abjeto e contribuem para isso através de um processo educativo cis-heterossexista, "por um currículo oculto 
comprometido com a imposição da heterossexualidade compulsória" (MISKOLCI, 2016, p. 35). Levar para a escola obras que questionem esse status quo cis-heterossexual de alguma maneira é visto, pois, como algo subversivo, indesejável e perigoso, que é preciso neutralizar. Como é notável na construção do projeto "Escola sem partido", no projeto de lei 504/2020 da ALESP.

Sabemos que o ensino de literaturas nas escolas pode(ria) ser realizado de um modo democrático, incluindo vivências, experiências de sujeitos historicamente subalternizados. Dessa forma, seria possível contribuir para que houvesse reflexão sobre o preconceito de modo que ele, um dia, não seja normalizado em nossa sociedade. Sabemos que isso não ocorrerá do dia para a noite e temos a consciência de que é preciso e urgente fomentar tais discussões, apresentar autores, compositores e obras, no sentido mais amplo, que contribuam para esse intento. A partir do nosso campo de trabalho e pesquisa, ensino de literaturas, temos consciência de que os letramentos literários são um caminho profícuo para alcançarmos visibilidade e humanização.

Para reivindicar a inclusão LGBTIA + na educação básica e nas listas de vestibulares, há, ainda, outra via tão importante quanto a reflexão sobre representatividade, conscientização, combate a preconceitos e a violências trans-homofóbica. Trata-se das contribuições que pessoas e temáticas LGBTIA + têm a oferecer à educação literária, ensino de literaturas e práticas de letramentos literários em si, por meio da diversificação dos saberes. Refletindo sobre essa diversificação, emprestamos o conceito de ecologia dos saberes, apresentado por Santos (2007) como uma diversidade epistemológica do mundo, ao reconhecer limites e incompletudes de cada saber sozinho. Com esse conceito, Santos (2007, p.85), assim como nós, propõe que apenas a construção coletiva de saberes plurais e diversos é capaz de resolver problemas complexos.

Se os saberes hegemônicos, eurocêntricos, cis-heteronormativos não são capazes de oferecer respostas sozinhos para problemas sociais e linguísticos que seguem sem solução, talvez a inserção de saberes hoje negligenciados, como os saberes LGBTIA+, possa auxiliar. Ou seja, "a ecologia de saberes se baseia na ideia de que o conhecimento é interconhecimento" (SANTOS, 2007, p. 85) e na necessidade do reconhecimento de que todo conhecimento é limitado e incompleto.

É a partir dessa reflexão que entendemos que a inclusão e legitimação institucional dos saberes LGBTIA+ nas escolas e universidade não se limita apenas ao benefício que isso traria para pessoas LGBTIA+, que passariam a ser representados e, possivelmente, acolhidos na sociedade. Essa inclusão beneficia as instituições educacionais em si, pois, sendo mais diversas e plurais, conseguem ir além dos limites dos conhecimentos já instituídos e cristalizados. Santos (2007, p. 94) ainda traz uma "questão com especial interesse para educadores: qual seria o impacto de uma concepção de conhecimento pós-abissal (como uma ecologia de saberes) sobre as instituições educativas?". Na ausência de respostas definitivas, o autor reflete que, ao menos, ofereceria "uma visão mais abrangente tanto daquilo que conhecemos como daquilo que desconhecemos".

O reconhecimento do que desconhecemos, na ecologia dos saberes tal como apresenta Santos (2007), está ao lado do que nos oferece a linguística queer sobre a desorientação, segundo Borba (2020). Para ele, o pensamento queer desorienta e a "desorientação produzida por esse movimento é o que lhe confere força de crítica e intervenção", já que possibilita "repensar sentidos e práticas naturalizados", "estranhar sentidos estáveis [e] investir no desconhecido" (BORBA, 2020, p. 43, grifo nosso). Logo, neste artigo, já que nossas reflexões e análises partem da ausência e do silêncio das listas de leituras obrigatórias dos vestibulares, propomos o primeiro passo para a diversificação dos saberes: estabelecer perguntas, identificar e reconhecer o que desconhecemos, desorientar, rumar ao desconhecido e, a partir disso, oferecer nosso modesto trabalho de curadoria de possíveis obras LGBTIA+ para integrarem os ambientes escolares e (pré-)universitários.

Quanto poderíamos aprender sobre adoção, uma questão social importantíssima, com Rafael Sorrigotto em sua obra Dois Pais de Dois, em que narra a experiência complexa do processo de adoção de dois filhos por um casal de homens gays? Quanto podemos aprender com João W. Nery, em suas diversas obras, sobre as vivências e experiências de um homem trans que passou pela cirurgia de redesignação sexual? Quanto poderemos aprender sobre interseccionalidade com as letras e intervenções artísticas de Linn da Quebrada, uma pessoa que se define como "bicha, trans, preta e periférica. Nem ator, nem atriz, atroz. Performer e terrorista de gênero" (G1, 2016, n.p.)?

Em linhas gerais, quanto aprenderemos com as experiências e os saberes singulares e coletivos, não hegemônicos, negligenciados, não institucionalizados e não legitimados de: Stênio Gardel, com o seu romance A Palavra que Resta; Johny Hooker, com destaque à composição da música "Flutua"; poetas da obra Antologia Trans: 30 poetas trans, travestis e não-binários, especialmente o poema "O futuro é primitivo" (2017); slammers publicados na Coleção 
Slam - LGBTQIA+ (ALCALDE, 2019); Amara Moira; Laerte Coutinho; Caio Fernando Abreu; Jup do Bairro; Jarid Arraes; Juão Nyn; Cazuza; Liniker; Jaloo, Angélica Freitas, Cassandra Rios; Anderson Herzer; Majur; Luana Hansen; Pablo Vittar; Bianca Manicongo; Ventura Profana; e tantos e tantas outros/as que nos fogem?

Destacamos, por fim, o ensurdecedor silêncio, a ausência, o esquecimento e o apagamento de muitos grupos sociais e temáticas LGBTIA+, tal como nas listas dos vestibulares, em nossa modesta lista acima. Ao contrário desse fato depor contra nossos argumentos, ele os reforça: precisamos rumar ao desconhecido, ao plural, ao diverso e ao estranho coletivamente, pois ninguém detém respostas completas e definitivas. Reconhecemos os limites dos nossos conhecimentos e apelamos para a construção de interconhecimentos contra-hegemônicos a partir de mais e mais sujeitos e grupos subalternizados. Em conformidade com Junqueira et al (2020, p. 212), reafirmamos que "educar contra a barbárie é desafiar as normas e os processos sociais, políticos e epistemológicos pelos quais alguns indivíduos são normalizados, enquanto outros são marginalizados", logo, faz-se necessário "desestabilizar relações de poder violentas, fender hierarquizações opressivas, perturbar classificações e questionar a produção de identidades reificadas". Afinal, "o Brasil de 2020 [e de 2021] está a exigir de nós uma mudança de enquadramento".

\section{CONSIDERAÇÕES FINAIS}

Ao buscar analisar a diversidade social em listas de leitura obrigatória para candidatos a vestibulares de universidades públicas de todas as regiões do Brasil, encontramos a reprodução dos padrões canônicos estabelecidos: maioria homens, cis-heterossexuais, brancos, de séculos anteriores. Há uma tímida presença de obras escritas por mulheres, negros/as e autores/as contemporâneos/as. Já os/as indígenas não aparecem como autores/as, apenas como personagens estereotipados/as. Quanto aos sujeitos e temáticas LGBTIA+, encontramos apenas silêncio, ausência, apagamento e, consequentemente, desumanização. Partimos, assim, para a interpretação dessa ausência.

As epistemes e políticas coloniais, de manutenção do status quo, fazem perdurar a estrutura e o cistema, sistema cis-heterormativo, de exclusão de qualquer tipo de vivência que fuja da norma cristalizada. Recentemente, o projeto de lei 504/2020 da ALESP (2020), que visava proibir publicidades com LGBTIA+, escancarou a vontade conservadora de invisibilizar pessoas de gêneros e sexualidades destoantes. Enquanto, no contexto educacional, o "Escola sem partido" busca constranger professores e perseguir debates sobre gêneros e sexualidades com o mesmo fim: invisibilizar e empurrar para os armários, becos e caixões as pessoas LGBTIA+. E são apenas dois pequenos exemplos.

$\mathrm{Na}$ contramão do que levianamente defendem esses grupos, percebemos que a presença LGBTIA+ nas escolas, especialmente nas aulas de literaturas, poderia, em síntese: envolver os estudantes às instituições Escola e Literatura, por se sentirem representados por elas; conscientizar e, com isso, contribuir para o combate das violências e das discriminações que vitimam LGBTIA +; e, não menos importante, diversificar os saberes, contribuindo para a reestruturação dos campos literário e pedagógico. Reconhecemos os limites dos nossos conhecimentos e, justamente por isso, apelamos para que mais vozes sejam ouvidas na construção de saberes e de interconhecimentos que, quanto mais diversos, tornam-se mais potentes. Se o conjunto de saberes já instituídos e legitimados não é suficiente para lidar com problemas sociais complexos, é hora de rumar aos saberes contra hegemônicos, negligenciados, de culturas apagadas e silenciadas.

Nesse sentido, compreendemos que instituições públicas de ensino superior, como autarquias, têm o importante papel, em momentos canhestros de governos retrógrados e autoritários, de criar legitimidade para o trabalho plural com saberes diversos, aqui especificamente os saberes literários LGBTIA +. A presença de obras, autores e/ou temáticas LGBTIA+ nas listas dos vestibulares dessas instituições teria efeito retroativo nas escolas e tiraria o peso das costas de professores, constantemente atacados e perseguidos por qualquer comentário sobre raça, gênero ou sexualidade. Porém, na conjuntura em que projetos, como o "Escola sem partido", fazem uso da "neutralidade ideológica" como estratégia para implementar uma educação conservadora e autoritária, o silêncio e omissão das instituições democráticas pode desempenhar um papel de conivência com esses projetos. 


\section{REFERÊNCIAS}

ALBUQUERQUE, G. (2018). Literatura e escola - as poéticas ameríndias em condição insular. In: SILVA, S. B. B. da; PEREIRA, J. N. (Orgs.). Língua portuguesa e literatura no livro didático: desafios e perspectivas. Campinas: Pontes Editore.

ALCALDE, E. (Org.). (2019). Coleção Slam - LGBTQIA+. São Paulo: Autonomia Literária.

ALESP. (2020). Projeto de lei 504/2020. 05 de agosto de 2020. Disponível em: https://www.al.sp.gov.br/ propositura/? id=1000331594. Consultado em 10/05/2021.

AMORIM, M. Á. de. (2017). Ensino de literaturas: perspectivas em linguística aplicada. 1. ed. Campinas: Pontes Editores.

ANTOLOGIA Trans. (2017) 30 poetas trans, travestis e não-binários. São Paulo: Invisíveis Produções.

BORBA, R. (2020). Linguística queer: algumas desorientações. In: BORDA, R. (Org.). Discursos Transviados: por uma linguística queer. São Paulo: Cortez.

BUTLEIN, M. (2019). "Qual a formação de professores para ensinar literatura?". In: MELLO, Cláudio; SEGABINAZI, Daniela Maria; OLIVEIRA, Gabriela Rodela de (Orgs). Literatura e ensino: desafios contemporâneos. Guarapuava: Unicentro, p. $17-41$.

BUTLER, J. (2017). Problemas de gênero: feminismo e subversão da identidade. Trad. Renato Aguiar. 13 ed. Rio de Janeiro: Civilização brasileira.

FERNANDES, E. R. (2017) "Existe índio gay?": a colonização das sexualidades indígenas no Brasil. Curitiba: Editora Prismas.

GONZALES, L. (2020). Por um feminismo afro latino americano: ensaios, intervenções e diálogos. Organização RIOS, Flávio; LIMA, Márcia. $1^{\text {a }}$ ed. Rio de Janeiro: Zahar.

G1. (2016). De testemunha de Jeová a voz do funk LGBT, MC Linn da Quebrada se diz "terrorista de gênero". 12 de setembro de 2016. Disponível em: http://g1.globo.com/musica/noticia/2016/09/de-testemunha-de-jeova-voz-do-funk-lgbt-mclinn-da-quebrada-se-diz-terrorista-de-genero.html. Consultado em 09/05/2021.

HOOKS, B. (2013). Ensinando a transgredir: a educação como prática de liberdade. Trad. Marcelo Brandão Cipolla. São Paulo: Editora WMF Martins Fontes.

JUNQUEIRA, R. D. et al. (2020). Políticas Educacionais de Gênero e Sexualidade no Brasil 2020: enquadramentos e enfrentamentos. In: FACCHINI, Regina; FRANÇA, Isadora Lins (orgs.). Direitos em Disputa: LGBTI+, poder e diferença no Brasil contemporâneo. Campinas, SP: Editora da Unicamp.

LUGONES, M. (2020). Colonialidade e gênero. In: HOLLANDA, Heloisa Buarque (org.). Pensamento feminista hoje: perspectivais decoloniais. Rio de Janeiro: Bazar do Tempo, p. 52-83.

MALDONADO-TORRES, N. (2007). Sobre la colonialidad del ser: contribuciones al desarrollo de un concepto. In: CASTROGOMÉZ, Santiago; GROSFOGUEL, Ramon. Orgs. El giro decolonial: reflexiones para una diversidad epistémica más allá del capitalismo global. Bogotá: Siglo del Hombre Editores; Universidad Central, Instituto de Estudios Sociales Contemporáneos y Pontificia Universidad Javeriana. Instituto Pensar, p. 127-159.

MAZZARO, D. (2021). Por uma educação lingüística queer: estranhando conceitos e práticas. Gragoatá, Niterói, v.26, n.56, p.1052-1084. Disponível em: https://doi.org/10.22409/gragoata.v26i56.49224. Acesso em: 22/10/2021.

MISKOLCI, R. (2016). Teoria Queer: um aprendizado pelas diferenças.2 ed. Belo horizonte: Autentica editora: UFOP Universidade Federal de Ouro Preto.

MOIRA, A. (2017). "Prefacio: A língua pelos nossos corpos" In: Antologia Trans: 30 poetas trans, travestis e não-binários. São Paulo: Invisíveis produções.

MOITA-LOPES, L. P. da. (1994). Pesquisa interpretativistas em linguística aplicada: a linguagem como condição e solução. Revista DELTA, São Paulo, v. 10, n. 2. pp. 329-338. 
MOITA LOPES, L. P. (Org.). (2006). Por uma Linguística Aplicada Indisciplinar. São Paulo: Parábola Editorial, 279 p.

MOTT, L; MICHELS, E. (2019). Relatório 2018: Assassinatos de LGBT no Brasil [Internet]. Brasil: Grupo Gay da Bahia - GGB. Disponível em: https://homofobiamata.files.wordpress.com/2017/01/relatc3b3rio-2016-ps.pdf. Acesso em 04/05/2021.

QUIJANO, A. (2005). Colonialidade do poder, eurocentrismo e América-Latina. In: LANDER, E. (org.). A colonialidade do saber: eurocentrismo e ciências sociais. Perspectivas latinoamericanas. Ciudad Autónoma de Buenos Aires: Colección Sur Sur, CLACSO, p. 107-130.

QUIJANO, A. (2005) Colonialidad del poder y clasificación social. In: LANDER, Edgardo (org.). A colonialidade do saber: eurocentrismo e ciências sociais. Perspectivas latinoamericanas Ciudad Autónoma de Buenos Aires: Colección Sur Sur, CLACSO, p. 93-126.

RAJAGOPALAN, K. (2003) Linguagem e ética: algumas considerações gerais. In: linguagem, identidade e a questão ética. São Paulo: Parábola Editorial, p. 15-22.

Por uma educação linguística crítica:

REZENDE, N. L. de. (2013) O Ensino de Literatura e a Leitura Literária. In: DALVI, M. A.; REZENDE, N. L. de.; JOVERFALEIROS, R. (Orgs.). Leitura de Literatura na Escola. São Paulo: Parábola.

ROCHA, L. L. (2020). Desfazendo o privilégio cis-heteronormativo no ensino de inglês na escola pública. In: BORDA, Rodrigo (Org.). Discursos Transviados: por uma linguística queer. São Paulo: Cortez.

ROJO, R. H. R. (2006). Fazer Linguística Aplicada em Perspectiva Sócio-histórica: privação sofrida e leveza de pensamento. In: MOITA-LOPES, L. P. (Org.). Por uma linguística aplicada indisciplinar. São Paulo: Parábola Editorial.

SANTOS, B. de S. (2007). Para além do pensamento abissal: das linhas globais a uma ecologia de saberes. Novos estudos - CEBRAP, São Paulo, n.79, p.71-94, Nov. 2007. Disponível em: https://doi. org/10.1590/S0101-33002007000300004.

SCARAMUCCI, M. V. R. (2004). Efeito retroativo da avaliação no ensino/aprendizagem de línguas: o estado da arte. Trabalhos em Linguística Aplicada, Departamento de Linguística Aplicada, Unicamp, n. 43 (2), p 203-226.

SOUZA, A. L. S. (2011). Letramentos de reexistência: poesia, grafite, música, dança: hip-hop. São Paulo, SP: Parábola, 171 p.

STREET, B. V. (2014) Letramentos sociais: abordagens críticas do letramento no desenvolvimento, na etnografia e na educação. BAGNO, M. (Trad.). São Paulo: Parábola.

STF. (2019). STF enquadra homofobia e transfobia como crimes de racismo ao reconhecer omissão legislativa. 13 de junho de 2019. Disponível em: http://portal.stf.jus.br/noticias/verNoticiaDetalhe.asp?idConteudo=414010. Consultado em 10/05/2021.

THOMAZ, D. (2018). Reduzida por homicídios, a expectativa de vida de um transexual no Brasil é de apenas 35 anos. 30 de janeiro de 2018. Disponível em: https://epoca.globo.com/brasil/noticia/2018/01/reduzida-por-homicidios-expectativade-vida-de-um-transexual-no-brasil-e-de-apenas-35-anos.html. Consultado em 10/05/2021.

VICENTINI, M. P. (2015). A redação no ENEM e a redação no $3^{\circ}$ ano do ensino médio: efeitos retroativos nas práticas de ensino da escrita. 2015. 264 p. Dissertação (mestrado) - Universidade Estadual de Campinas, Instituto de Estudos da Linguagem, Campinas, SP. Disponível em: http://www.repositorio.unicamp.br/handle/REPOSIP/269558. Acesso em: 10 jan. 2021.

WALSH, C. (2009). Interculturalidad crítica y pedagogia de-colonial: apuestas (des)de el in-surgir, re-existir e re-vivir. Revista (entre palabras). Quito, p. 1-29.

Recebido: $14 / 6 / 2021$

Aceito: $22 / 10 / 2021$

Publicado: 26/10/2021 